\title{
BIM-VR Framework for Building Information Modelling in Engineering Education
}

\author{
https://doi.org/10.3991/ijim.v14i06.13397 \\ Jing-Ying Wong $(\bowtie)$ \\ University of Nottingham Malaysia, Selangor, Malaysia \\ JingYing.Wong@nottingham.edu.my \\ Chun-Chieh Yip \\ Universiti Tunku Abdul Rahman, Selangor, Malaysia \\ Su-Ting Yong \\ University of Nottingham Malaysia, Selangor, Malaysia \\ Andy Chan, Sien-Ti Kok, Teck-Leong Lau, \\ Mohammed T. Ali, Essameldin Gouda \\ University of Nottingham Malaysia, Selangor, Malaysia
}

\begin{abstract}
With the advancement of information technology, Building Information Modeling (BIM) is evolving fast and play an essential role in Architecture, Engineering, Construction, Owner and Operators (AECOO) industry. Universities play an important role in the current BIM transition in construction projects as well as to embrace Industry 4.0. In this research, immersive Virtual Reality (VR) in BIM offer a unique, supportive environment for the user experience in visualizing and collecting data from the model. With Virtual Reality (VR), engineering education has a major breakthrough. Immersive interactions, stereoscopic 3D, real time multisensory simulations, virtual explorations, synchronous communications, data analytics and visual analysis - all these are impossible without VR. VR offers a student-centred learning environment that promotes active and collaborative learning, situated within simulated real-world contexts.
\end{abstract}

Keywords-BIM-VR Framework, Virtual Reality, Engineering Education

\section{Introduction}

Currently, Building Information Modelling (BIM) is introduced into the Architecture, Engineering, Construction, Owner and Operator (AECOO) sector at a rapid pace and tends to be seen as a cutting-edge technology and processes. Engineering education always strives to follow the interests of the construction industry and especially now BIM is a very important. According to Sabongi and Arch [1], the academic community moves more deliberately and thoughtfully to incorporate new technologies and to offer new courses. 
Universities must focus on the strategy of using BIM as an innovative technology to allow the acquisition of new skills for the students and prepare them for their future activities in a more competitive world. School is an important driver for the growth of BIM knowledge [2]. Students' learning and teacher's teaching can be enhanced by appropriate advance technology. Technology could encourage more independent and active learning among students [3]. A key reason for the use of technology within a learning situation is to enhance the quality of learning and teaching [4].

Today's students are the "digital generations". They are born and grow up in a digital and technology-savvy world. Their learning styles have changed, e.g. preference of multitasking and social media awareness. Education and technology are always interconnected so it would be important to explore how technologies could be embraced by education. The digital generations obviously love modern technologies, and are positive towards online education and learning with technologies. For this reason, the virtual reality (VR) technology is a step to bridge our pedagogy and communication between the academia and nowadays students.

BIM course was introduced to Year 3 Civil Engineering students since 2015 as an optional course at the University of Nottingham. Significant changes are being introduced to BIM due to the major contribution of BIM in the AECOO industry. The course is to provide detailed knowledge and understanding of the fundamental concept of BIM to be applied in the life cycle of buildings/ infrastructure, which includes planning, design, construction, operation and demolition.

In addition, this module provides students with an opportunity to use digital design, planning, analysis and presentation tools to support the collaborative design and planning of a reinforced concrete building (e.g. an office building, a hospital, an airport terminal). Student work in groups on their design project to produce detailed architectural/structural design and documentation. Autodesk Revit software is an intelligent model-based process to plan, design, construct, and manage buildings and infrastructure. Then, Revit model is brought into Virtual Reality space by Oculus Rift Touch. It helps to create an interactive walk-through and provide students with a realistic sense on the actual live in the simulated environment. BIM shows a building at every step of its development and illustrate design, construction, and materials in detail. The embedded capacities of BIM make it a dynamic platform that allows multiple groups in different locations to work on projects.

Precise planning along with technologies are essential to make this course successful and effective to the students. It is essential to create interactive lesson for the new generation as they are growing up with technologies. Integration of the advanced technologies into BIM course teaching helps to deliver the course in more effective, engaging and interactive ways. It helps to improve the teaching and learning which would benefit both students and the University. In this research, VR will be integrated into BIM teaching and learning for an effective in and out of classroom engagement.

The aim of this research is to explore the teaching and learning experience by integrating Virtual Reality into Building Information Modelling (BIM) course in the Department of Civil Engineering at the University of Nottingham Malaysia (UNM). A BIM-VR framework is designed for modelling the existing structures. The framework makes use of object-based parametric modelling software packages to develop a data- 
rich model for existing structures from extant documents and available knowledge. It is to reduce time, cost and increase quality in modelling of complete existing structures in terms of architecture, structural and interior design, mechanical, electrical and plumbing systems.

This study acts as a stepping stone to help more educators at UNM to explore the potential benefits brought by VR in other educational settings. VR can be employed to give immersive experiences to medical students, mechanical engineering students, student pilots, etc. This will result in better graduates who are knowledgeable in their respective fields meanwhile opening for new research areas on certain subjects.

In addition, students are able to experience the real construction process in BIM course with the integration of VR, prepare the future professionals who will be experts in BIM, good teaching and learning experience and hence improve the offered BIM course, and also to attract the outsider investors to invest in the BIM technologies to support the future BIM research.

\section{$2 \quad$ Literature Review}

\subsection{Building Information Modeling (BIM)}

Building Information Modelling (BIM) is a terminology developed to illustrate a broad set of discipline-specific software packages that handle all phases in the project lifecycle (LC) [5], representing as a semantically enriched and consistent digital building models [6];[7]. It can also stand for building information management which the control of the processes in the built and used model [8] and for building information marketing [9]d.

On the other hand, others could argue that BIM is the process of creating information about (future) building. This is even acknowledged in the BIM maturity levels [5];[10]. The US National Building Information Modelling Standard defines BIM as "A digital representation of physical and functional characteristics of a facility and a shared knowledge resource for information about a facility forming a reliable basis for decisions during its life-cycle; defined as existing from earliest conception to demolition" [11].

BIM maturity levels are a broadly accepted concept in the understanding of BIM, where Level 0 utilizes only 2D drawings and shared among different stakeholders either in a digital or paper format, Level 1 typically consists of 3D conceptual CAD drafting and 2D CAD drawings for approval of building documentation and the 3D Model is not shared among project team members, Level 2 is distinguished by collaborative working, and requires "an information exchange process which is specific to that project and coordinated between various systems and project participants" [12], and Level 3 that represents the full collaboration between all disciplines by means of using a single, shared project model which is held in a centralized repository, in which all parties involved can access and modify with no risks of any clashes and conflictions. 
BIM software packages have provided the opportunity for interoperability, the ability to exchange/share information between separate computer programs without any loss of content or meaning [13]. They also couple project organizations together for an existing building [14], since in practice the benefits of BIM are based on the value added by the creation of an integrated model [5], which provides a resource for data sharing in a facility to enhance in facility management, operation and maintenance [15]. For instance, an air conditioning unit within a BIM would also contain data about its supplier, operation and maintenance procedures, flow rates and clearance requirements [15];[16].

BIM usage for existing structures has been widely studied in [17];[18] and its benefits have been widely espoused.

\subsection{Virtual Reality (VR)}

Virtual Reality is commonly referred to as a set of technological devices which include 'computers, head-mounted displays, headphones, and motion-sensing gloves' [19]. It is a technology that immerses the user into a computer-simulated environment establishing the sense of being transported into an utterly distinctive reality. The use of VR in simulating structure buildings has been introduced multiple times in the past [20];[21];[22] as well as owing to the noticeable advancement of technology in the past couple of years. The implementation of VR in various applications nowadays has become smoother.

Gaming development engines are used to facilitate the process of developing a VR environment, by using scripting languages such as 'C\#' (C-Sharp) and 'Javascript' to manipulate objects in the three-dimensional (3D) reality. Scripting languages could also be merged with additional libraries to allow the retrieval of specific information from the database describing certain objects; the gaming development engines compile these scripting languages into native codes to ensure fast and reliable performance [23]. VR headsets are the hardware used to deliver the VR experience to the user, a head-mounted display (HMD) that allows the user to interact with the virtual environment in first-person view (FPV) with the help of tracking sensors.

Schrader [24] has established 'learning about technology', 'learning from technology', 'learning with technology' and 'learning from technology' which defines the different types of interactions either between the users and the content of the world or the users themselves [25]. VR system is developed to promote Engineering Education. VR can be used in any teaching when the real thing is high risk, impossible, inconvenient, too time-consuming or too costly [26]. VR helps to create an interactive walk-through and provide students with a realistic sense on the actual live in the simulated environment. With the VR, student's motivation can be enhanced and make learning experience more interesting. In addition, VR helps to improve group work skill and self-directed learning in problem-based learning narratives [27]. 


\subsection{Integrating VR in BIM}

The need for VR in BIM is increasing due to the advantages and value added to the BIM environment. The use of VR improves visualization and provides an accurate height measurement of the user, this technique is achieved through usage of the tracking sensors, allowing a proper scaling with the actual dimensions of the building for a better sense of relativity, which immerses the user in the virtual environment giving a better sense of the surrounding lengths and heights e.g. the distance between two columns, or floor to ceiling height. As VR is making use of the height of the user in the virtual environment, different safety aspects can be assessed e.g. railings heights, such that assumption can be made on whether the building is safe to be used in its current condition in reality.

Other aspects of safety such as routes and lengths of emergency paths [28] can be planned and tested in the virtual environment to allow sufficient time to escape by simulating the average speed and step length of a user. Moreover, this integration allows easier and faster viewing of the interior design of the existing structure. Therefore, this technique provides an opportunity to assess the potential of any change or retrofitting processes that are planned in the future.

Better visualization in VR provides better opportunity for application in the real estate and property development industries. VR allows showcasing of properties to be sold or rented, as the estate buyer can go through the building in a tour to view every aspect and component of the building with its unique properties (e.g. different types of floors are identified as oak or concrete) remotely, without the need to directly visit the real estate company. Mobile access could also be implemented to allow different overseas consultants to visit the existing structure for facility management and maintenance procedures without the need to travel. Therefore, this technique reduces the transportation time, costs and efforts in presence of the VR headset without losing any of the essential BIM concepts and semantically rich models.

Gee [29] has indicated that an immersive, intelligent and digital environment provides an improved platform in the area of education. In addition, Michael and Chen [30] have demonstrated that serious games (is a game designed for the benefit of the user and marginally the user's entertainment) can provide the upcoming learners with an environment that motivates understanding and visualizing. Various research in this area recognized the benefit of some of the serious games in the education industry.

\section{$3 \quad$ Methodology}

\subsection{Designed BIM-VR framework}

BIM-VR framework can be carried out with any computer-based VR headset, which consists of a head-mounted display and tracking sensors connected to a computer device and wireless controllers. However, mobile-based VR headsets will not be compatible as they only operate with the restrictions limited to the ability of the mobile phone placed in the HMD that does not have the ability in terms of processing 
power to run the final application. Moreover, controllers are not widely available for commercial use in the case of a mobile-based VR headset.

In this research, the chosen BIM software is Autodesk's Revit ${ }^{\circledR}$ which is widely used in the industry and can be used to export to formats that will be favourable during the framework use. The computer graphics program used as a rendering engine is Autodesk's 3DS MAX ${ }^{\circledR}$ which is used to convert Autodesk material library (AMC) materials to standard materials, through an available converter plug-in, which can be processed and visualized in the game development engine. Other alternatives exist such as rendering through a third-party renderer named NVIDIA Mental Ray which is readily available in most versions of 3DS MAX ${ }^{\circledR}$, but it was discontinued after the 2017 version.

Unity ${ }^{\circledR}$ is the game development engine used which allows manipulation and scripting to form a platform to move through the existing structure in first person view. It is also used to develop and integrate the $360^{\circ}$ interior inverted spheres. In addition, Unity ${ }^{\circledR}$ provides no restriction on tools that can be added through objectoriented programming (OOP) using $\mathrm{C} \#$ programming language in Unity ${ }^{\circledR}$ to convert to the VR. The hardware used to run the application produced by Unity ${ }^{\circledR}$ is Oculus Rift ${ }^{\circledR}$ CV1 consists of a HMD, 2 touch Controllers (one for each hand) and 2 infrared tracking sensors, which keep track of movement of the head and each hand.

Oculus Rift ${ }^{\circ}$ was chosen as it has a built-in headphone, which is useful in the immersive environment when compared with its competitors that require an external headphone to simulate sounds. The touch controllers in the Oculus Rift $®$ can sense the movement of individual fingers. Therefore, Oculus Rift@ provides a more realistic performance in the virtual environment. In addition, it provides wide range of available resources and libraries that reduce the workload required to finish a specified task.

Designed BIM-VR framework can be implemented using any BIM software, computer graphics program (rendering engine) and game development engine. The general flow of the designed BIM-VR framework is shown in Fig. 1. The framework is started with 3 different stages that are later combined into one model and accessed by the user; 1) Integrate VR into unity; 2) Create the visualization environment for the interior of the model; 3) Create the exterior BIM Model. The three stages were executed parallelly as demonstrated by the flowchart and each stage is further explained.

BIM-VR framework is designed to allow a brief description of items in the structures as the user line of sight crosses them e.g. provision of information for the materials used in the construction of the existing structure. It breaks the language barrier as it reduces the need for verbal communication and favors the visual communication of data and building related information through the data input into the database e.g. diameter, flow and pressure in a pipe is generated as a pop-up when the line of sight of the user meets the specified pipe. These data are extracted by using the scripting languages in the gaming development software by connecting to the dedicated server that inputs the data directly from the BIM software with the help of the corresponding BIM software Application Programming Interface (API). The main feature of the server is the data could be easily updated or appended by the user on the BIM model using the object based parametric software and directly viewed in the VR environment. 
Designed BIM-VR Framework provides access to the BIM model and its data with no compatibility complications when transferring between two different BIM modelling software packages, thus eliminate the need of exporting the model into the Industry Foundation Classes (IFC) format and imports it to view on the other software package such that it provides a readily executable file (EXE) format that can be viewed on any platform.

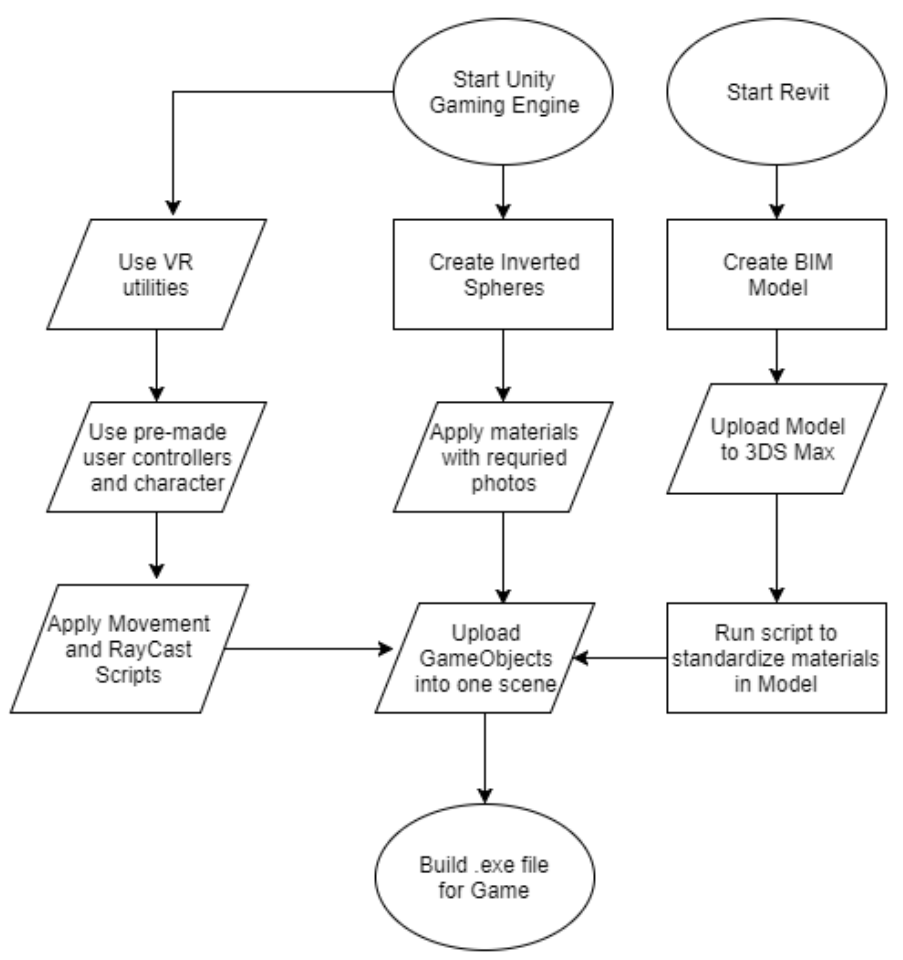

Fig. 1. Flowchart demonstrating the general flow of BIM-VR framework

Exterior and MEP modeling: The first step to produce a model of an existing structure in VR is to transfer the 2D extant drawings into a BIM modeling software on which architectural, structural, mechanical, electrical and plumbing models co-exist at the same time, without the need to model the interior design which is extremely timeconsuming and difficult to model with high accuracy unless point cloud-based methods which are of very high cost are implemented. Fig. 2 demonstrates the modelled exterior design of the Trent Building in the University of Nottingham Malaysia that is based on actual construction 2D CAD drawings. 


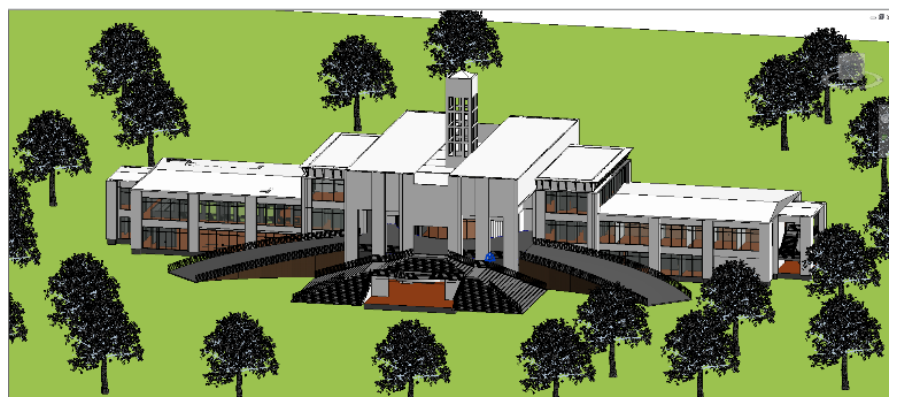

Fig. 2. Exterior model in Autodesk Revit® Software

Non-geometric information such as materials of building components is also added. The accuracy of the existing structure is viewed in VR. Therefore, the simulation is limited to the construction accuracy relative to the drawings at construction time, unless the drawings are updated after construction to produce an accurate representation of the existing structure. Modelling the exterior and MEP provides realism and better virtual environment as it allows the user to freely move in the first-person view and discover every element of construction in the existing structure. Fig. 3 shows a MEP system in one of the rooms of the Trent Building.

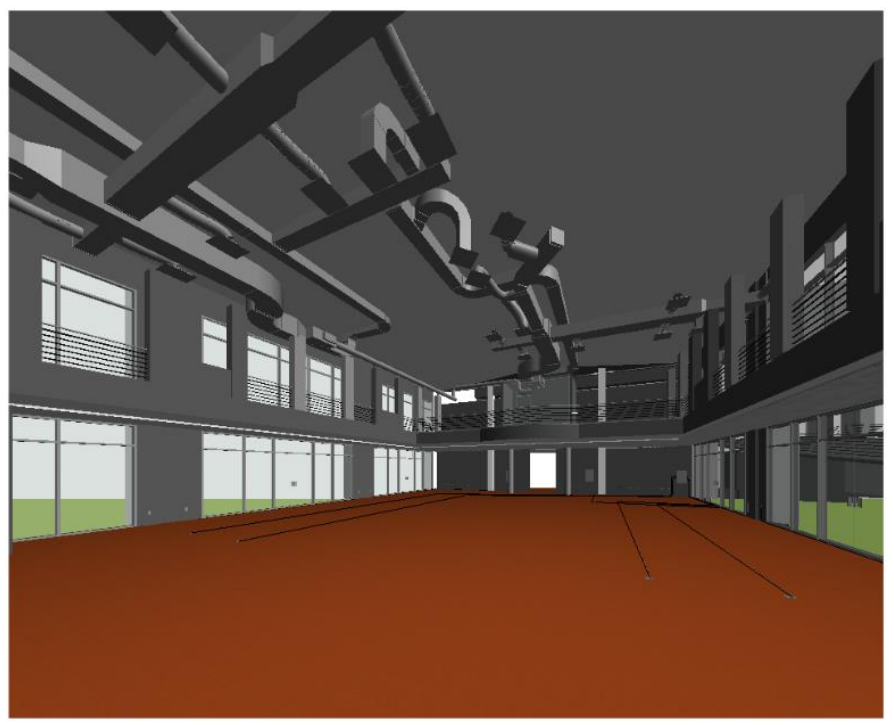

Fig. 3. Sample Air Conditioning System for one of the rooms in Autodesk Revit® Software

Exporting process: Exporting the Revit® 3D model to Filmbox format (.FBX) which is then imported in 3DS MAX ${ }^{\circledR}$ as shown in Fig. 4, ensures all desired objects in the existing structure are visible. For versions of 2017 and before a NVIDIA® Mental Ray ${ }^{\circledR}$, plug-in readily exists in $3 D$ S MAX ${ }^{\circledR}$ which uses ray tracing to render the model. Without this plug-in, textures will be missing in the model [31]. 


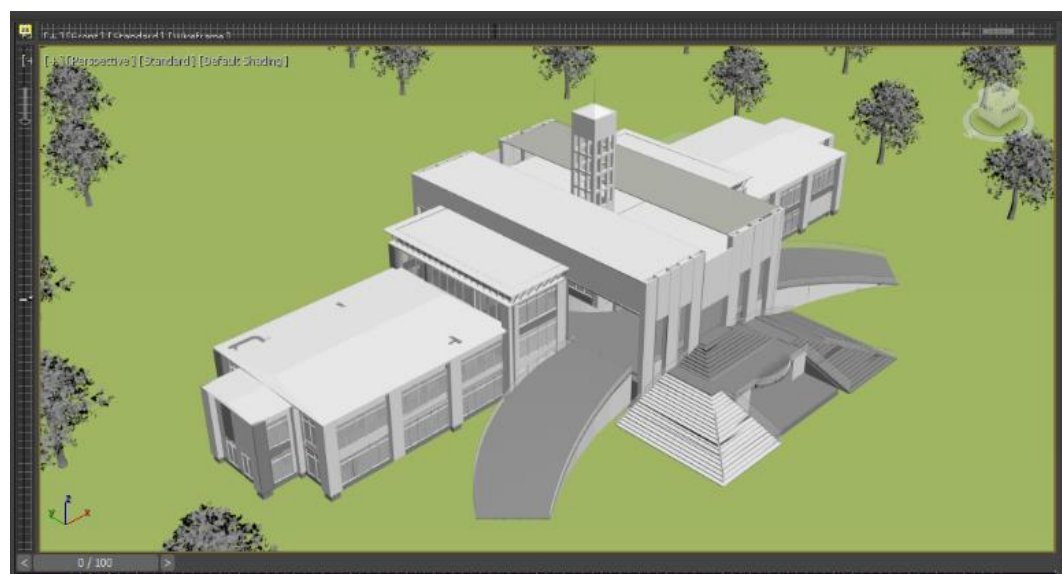

Fig. 4. Isometric view of exterior model in Autodesk 3DS max ${ }^{\circledR}$

The model is then exported to .FBX format again which can be directly imported into Unity ${ }^{\circledR}$ in assets. However, this method does not produce textures for all components, so some textures are found to be missing. Material standardization is important to solve the problem of losing parametric information during the migration of a proprietary model into the Unity® based virtual reality platform. A plugin-in automatically identifies all the Autodesk material types inside the Revit model and standardizes them based on Standard Material .So, the end result in Unity® can be visualized in Fig. 5 [32].

A set of tools is designed in the virtual environment to facilitate the users' extraction of further detailed data. The provided toolkit contains

1. Length-measuring equipment,

2. Angle-measuring equipment,

3. Simple Calculator and

4. Material detecting equipment as shown in Fig. 5.

The length-measuring tool calculates the distance between two points whereas angle-measuring tool requires three points (A, B and $\mathrm{C}$ ) and measures the respective angle between vector $\mathrm{AB}$ and vector $\mathrm{BC}$. Simple calculator is added to assist the user with basic mathematical calculations, thus defying the need to remove the HMD for any calculations. In addition, a material detection tool is designed to identify the type of material incorporated into each building components in the existing model. A panel is also attached alongside the toolkit to guide the user on how to use each tool and automatically displays the returned results by the respective tool. This toolkit provides accurate data extraction technique from the existing structure while in the virtual environment with results of high accuracy that require no scaling or any form of manipulation. 


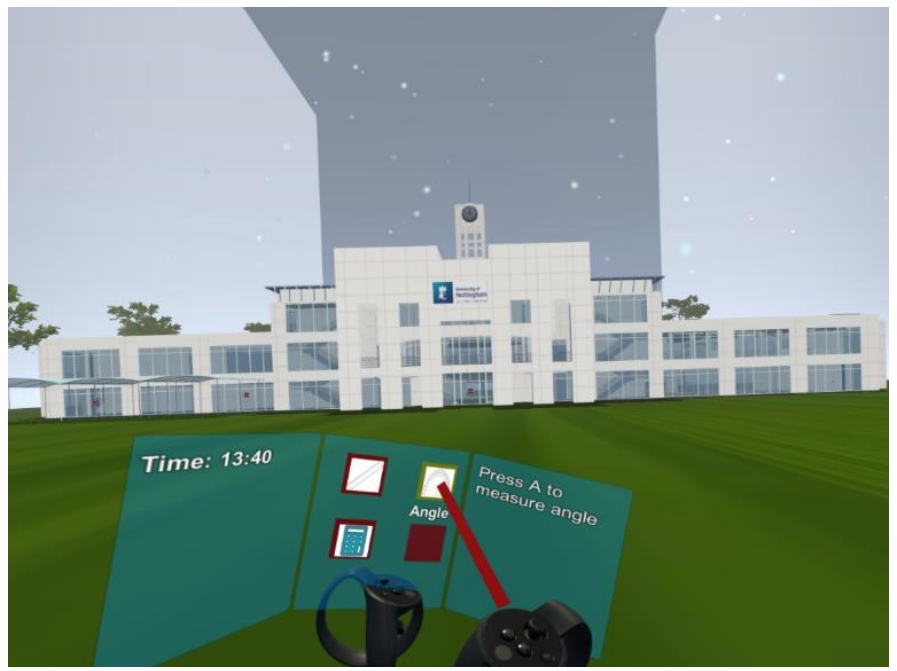

Fig. 5. Overview of BIM in unity and the integrated tool-kit with its different components

Interior design visualization: One of the most complex challenges in modelling an existing structure is modelling the interior design of an existing building. It is possible that certain brands of materials and components are not available when the modeller need to use them according to the existing project specifications [33]. Moreover, the work is extremely time-consuming to model the interior design piece by piece for any existing structure and is difficult to yield a model that is perfectly accurate in comparison to reality due to the regular undocumented changes in buildings. Ibrahim and Krawcysk[34] have pointed out that we need to wait until new components are available on the market if a building is to employ creative and innovative design solutions.

Hence, BIM-VR framework introduces the concept of an inverted sphere which utilizes a low cost 360-degree camera. An algorithm is established in the game development engine to project the 360-degree photos on a sphere in which the user is placed virtually in its centre. This advanced photogrammetric method ensures extremely high accuracy in comparison with all other commercially known techniques in nearly negligible time. The user can move smoothly in the interior of the existing building among pre-defined points to visualize the interior design with all its details. Moreover, the user with a press of a button can transfer to the free-movement environment to view things beyond the photogrammetric ability of the 360-degree image viewer such as MEP systems, which are above ceilings and inside walls. In Fig. 6 all the inverted spheres used in the building are shown independently from the building structure from a bird-eye's view. 


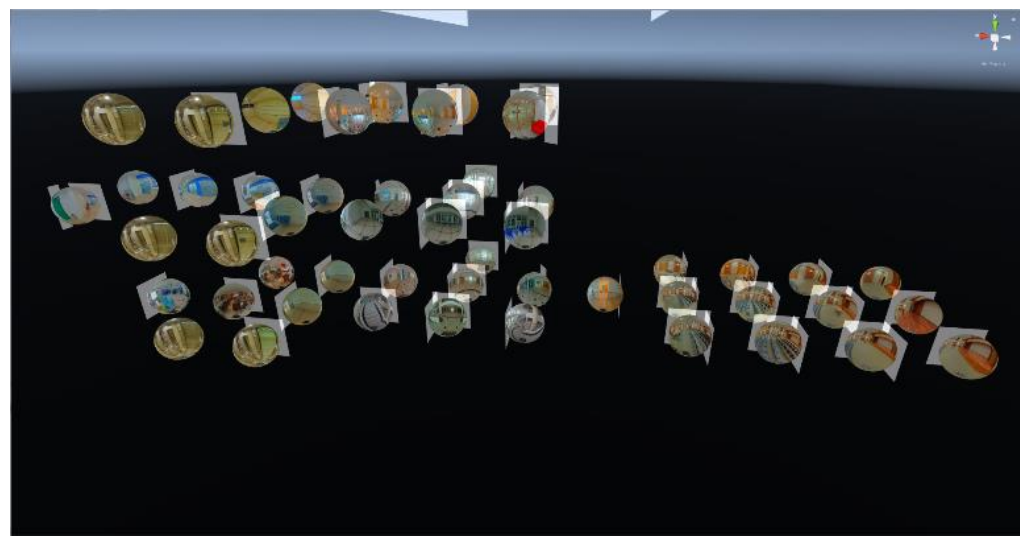

Fig. 6. Overview of all Inverted Spheres with different 360 images superimposed

VR integration methods: Using the BIM-VR framework provided by Oculus ${ }^{\circledR}$ rift for Unity® game engine three game objects were uploaded to the virtual environment, and several scripts were applied to these game objects to further enhance the user experience while using the environment created.

The first game object used is the first-person player controller (FPC), named in unity "OVRPlayerController", which provides a full visual model for the user and allows free movement using the touch controller's joystick for the user to be able to move freely inside the virtual environment while being able to view the surrounding through the head mounted display. The FPC game object is a parent object for 2 different game objects "ForwardDirection" and "OVRCameraRig".

Under the second game object there is the "TrackingSpace", a game object, which consists of another 6 children objects of interest as they track the users' left hand, right hand, left eye's view, right eye's view, center's view, and the whole user by adding further game objects as children under the following objects; the position and properties of each object that will be inherited and further used thus the usage of an OOP-based language.

The other two game objects used from Oculus ${ }^{\circledR}$ VR framework are the right hand's and left hand's controllers which were created by the oculus rift's team who applied scripts to them by stimulating movement of the buttons and joysticks in the virtual environment when applied by the user in the real world. Both controllers were added under the respective child game objects under the FPC parent one, which can all be demonstrated through the Unity ${ }^{\circledR}$ screenshot in Fig. 7. 


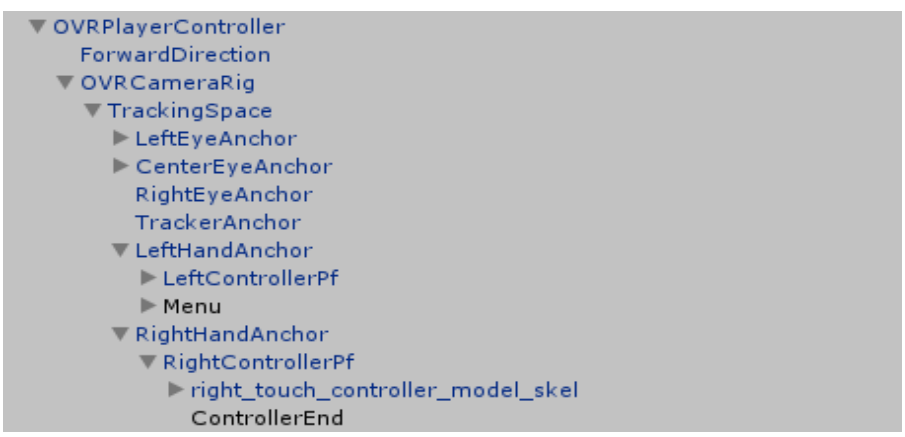

Fig. 7. OVRPlayerController game object with its children objects

Helping the user to perform specific functions when prompted, Unity ${ }^{\circledR}$ class "MonoBehaviour" raycasts were used from the tip of the right-hand controller pointing to objects in the environment the concept of inverted spheres. Interior models further enhance the BIM by adding more realistic components to the existing structure and help the user in visualizing the actual environment. The main problem with modelling the interior design is the lack of inventory of each interior model. These models differ in their structure and design; therefore, the designer is required to start creating the model from scratch since sometimes the documents related to this design are not provided [35] leading to increasing time, amount and complexity of the task.

The concept of inverted spheres is introduced in the BIM-VR framework to help the designer add the interior model achieving the visual advantage of having the interior model in the BIM for the existing structure. The concept is achieved by using a 360 camera that takes photos for the interior model of the building, and these photos are later added to the inverted spheres in the unity game engine which allows the user to move between these spheres in order to tour the building and examine the interior design of the building as well as transfer between the BIM, to observe the MEP, and return to the inverted spheres. Fig. 8 shows a zoomed in view on one inverted sphere with the relevant 360-degree photo superimposed.

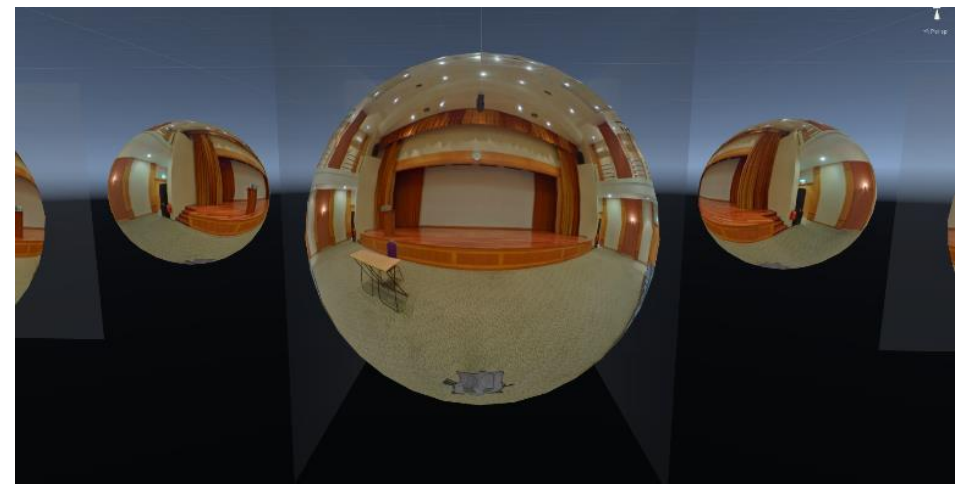

Fig. 8. A close view of one inverted sphere with its respective superimposed 360-degree image 
The Unity ${ }^{\circledR}$ game engine already provides a sphere game object. However, these spheres need to be modified via a script written and added to the 'Editor' folder under the main 'Assets' folder in unity to create a new 'InvertedSpheres' object that helps the developer to use it later.

The 'InvertedSpheres' class has a function that creates a graphical user interface (GUI) for the developer to choose the respective game object and to choose a certain radius of the sphere. This script also creates a mesh renderer that is applied to the inverted spheres. The main idea of this renderer is to invert the sphere so the user could stand in the center of the sphere and easily view the full 360-degree photo that covers the sphere by rotating using the HMD. An invisible plane is created to cover the whole sphere horizontally to provide a ground for the user to stand on while viewing the photos. Without this ground the user won't be able to stand at the center of the sphere as the sphere is empty from the inside. Additionally, the movement script is updated to prevent the user from moving when in the interior design view inside the spheres; as for realistic view the user needs to be always at the centre of the sphere to see the photos that represent the actual interior design in a certain area or room. The invisible plane is created by using the plane game object in Unity ${ }^{\circledR}$ game engine and the application of s transparent material.

After creating the inverted sphere, a material is created with the type of 'Unlit/Texture' and the texture added is the 360 -degree photo captured. This material is used to further enhance the quality of the photo using a 360-degree photo viewer. The number of spheres is equal to the number of photos taken by the user according to the respective number of views of the interior the user wants to provide.

The concept of movement between the spheres is achieved by adding extra invisible planes that are perpendicular to the horizontal plane. These planes are added depending on the spheres surrounding the current sphere that the user inputted. The spheres are equally placed and each sphere has a certain position depending on the user input. When the user looks at a certain direction and this direction allows the user to move into a different view of the interior design the user is prompted to press a button in order to view to the next view, this is achieved by having a raycast checking which invisible plane is the user pointing too and if the button is pressed the user is transferred to the center of the targeted sphere; therefore, it allows different views of the interior design and generalizes the concept of movement between the spheres; this process is demonstrated in the flowchart in Fig.9. For presentation purposes in this flowchart, 4 directions are only added, but the user can add infinite number of directions, including up and down, using the framework. 


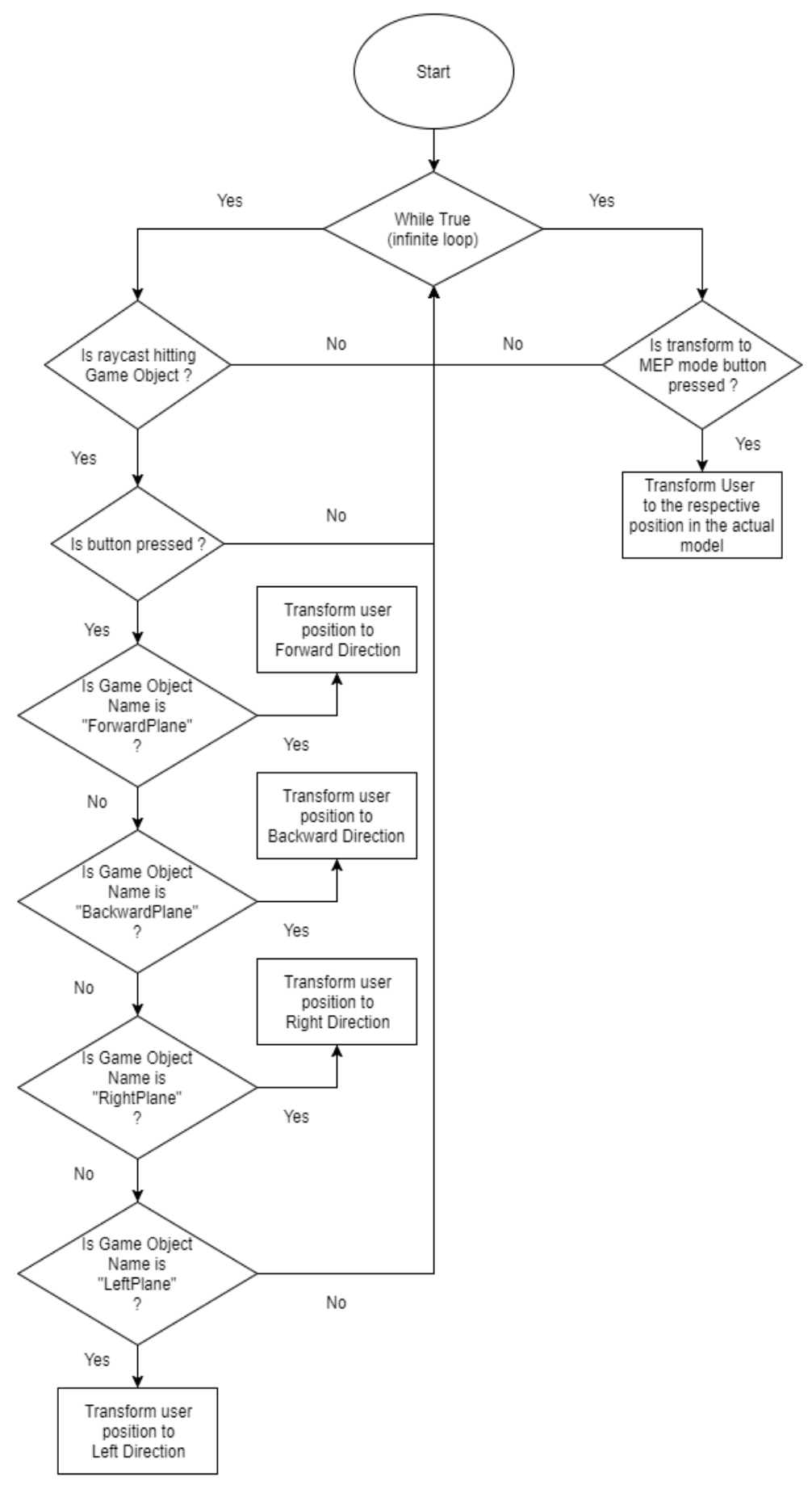

Fig. 9. Flowchart demonstrating the controls programmed on both controllers 
The switching between the interior views in the Inverted Spheres and the MEP (as shown in Fig. 10) in the model allows the user to retrieve information such as the specifications of MEP.

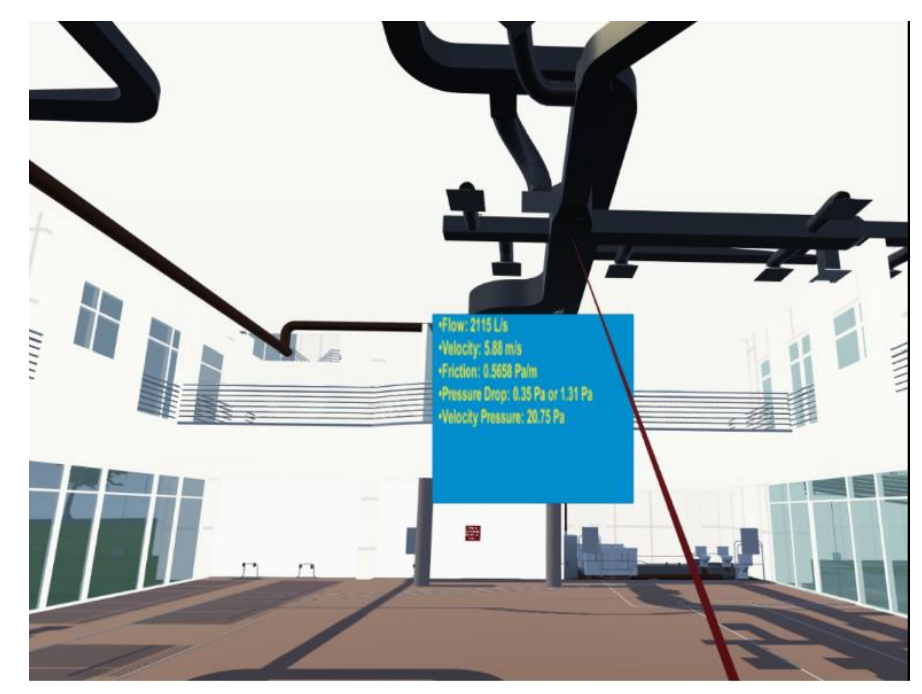

Fig. 10. Air conditioning system in the virtual environment and sample data extraction

Using the IS the user can visualize the interior of the BIM model accurately, and if data is needed to be extracted interiorly the user will be able to access the BIM model and use the toolkit to access the data. Using this method, the developer does not need to design the interior model as the IS visualization concept is achieved using a 360 camera to provide accurate results for the interior.

\subsection{Questionnaire survey}

VR has been integrated into BIM in teaching Civil Engineering through blended learning or hybrid virtual learning [36];[37]. Students are taught the fundamental concepts of BIM (e.g. life cycle of buildings - planning, design, construction, operation and demolition) and the functionality of BIM software. The 3D models in BIM allow students to feel space in a way that is not possible with traditional 2D drawings. Then, students can walkthrough and feel what it is like to be right inside the buildings that they have designed using Oculus Rift VR headset.

In VR, students are getting an immersive 360-degree view and they can "walk around" their new designs, e.g. future house, buildings and renovations. The idea is that students can sit inside a classroom, but walk virtually inside the models (using the VR headset) and evaluate every nook and cranny of something that does not exist physically, e.g. concealed conduits, wiring and building services. The technology also enables virtual interaction between various stakeholders in a project (e.g. architects, engineers, consultants and quantity surveyors) and the central maintenance of all sorts of data, hence to provide a holistic approach to construction projects. The immersive 
interactions in networked virtual environments are difficult or even impossible in traditional classrooms or lab settings. The level of immersion and control of learning experiences is not possible without VR.

A data collection and survey were conducted to ensure the credibility of this study. Questionnaire survey was adopted in this project to explore the teaching and learning experience by integrating Virtual Reality into Building Information Modelling (BIM) course in the Department of Civil Engineering at the University of Nottingham Malaysia (UNM). In this study, a quantitative survey is used to evaluate the students' experience in using the BIM. The survey was developed from the review of the literature and what the researchers thought to be significant in exploring a new application software in engineering. The questionnaire was administered online using Google Form and it was designed with a 5-point Likert scale: 1 (Strong Disagree), 2 (Disagree), 3 (Neither agree nor disagree), 4 (Agree) and 5 (Strongly Agree).

The survey was divided into two sections.

Section 1: Perception towards augmented reality and virtual reality

Q1: I can virtually travel to places that I may not able to visit in future.

Q2: I can travel through time and explore ancient civilization and construction industry.

Q3: I can practice skills in a safe and non-threatening virtual environment.

Q4: I am able to see and learn the hidden Mechanical, Electrical and Plumbing (MEP) features and thus enhance my understanding.

Q5: I am able to learn the safe features in the construction.

Q6: I can grasp Design concept more readily and retain the information for longer time.

Q7: I am fully focused on learning content and removed from distraction.

Q8: I am able to trigger my own creativity in design.

Section 2: Learning experiences

Q9: The objectives of the workshop were made clear/available to me.

Q10: The teaching methods used in the workshop help me to learn.

Q11: The method of assessment (coursework, practical, etc.) allows me to demonstrate what I have learned on the workshop.

Q12: The level of the workshop is about right.

Q13: The workload on the workshop is about right.

Q14: The teacher was approachable.

Q15: The teacher was an able communicator.

Q16: The teacher was patient in explaining things which seem difficult to grasp.

Q17: The teacher retained my interest.

Q18: The teacher was helpful and supportive.

Q19: The teacher encourages me to take responsibility of my learning.

Q20: Sessions were paced appropriately.

Q21: I am satisfied with the venue and time allocation for the module.

Q22: I am satisfied with the learning support provided by the teacher.

Data Collection: The sample of study was drawn from undergraduate civil engineering students registered in the BIM course. They are from year 1 to year 3 students 
age 19-21. The quantitative survey was administered at the end of the semester upon completion of the BIM course. The BIM course was conducted in the form of a compulsory BIM Group Design Project module in 13 weeks and 4 hours per week. The questionnaire was simple and it took approximate 10 minutes to complete. Students' participation was based on voluntary basis and no coercion was used. This is to adhere to the research ethical conduct that all human subjects are choosing to participate of their own free will. In addition, ethical standards also protect the confidentiality and anonymity of the human subjects. There were 57 students responded to the survey and the respond rate was good.

Data analysis: The data was analyzed using Microsoft Excel and IBM SPSS version 25. Descriptive statistics was presented using the bar charts and some statistical analyses were performed to construe the data.

\section{$4 \quad$ Results and Findings}

\subsection{Demographic information}

The students participated in this study came from a diversified spectrum of profiles. The students' demographic information is shown in Table 1. Most of the students participated in this study was male students (77\%), Year $3(65 \%)$ and Malaysian $(81 \%)$.

Table 1. Students' demographic information

\begin{tabular}{|l|c|c|}
\hline \multicolumn{1}{|c|}{ Gender } & Frequency & Percent \\
\hline Male & 44 & $77 \%$ \\
\hline Female & 13 & $23 \%$ \\
\hline Year of study & Frequency & Percent \\
\hline Year 1 & 2 & $3 \%$ \\
\hline Year 2 & 18 & $32 \%$ \\
\hline Year 3 & 37 & $65 \%$ \\
\hline Citizenship & Frequency & Percent \\
\hline Malaysian & 46 & $81 \%$ \\
\hline International & 8 & $14 \%$ \\
\hline Missing & 3 & $5 \%$ \\
\hline TOTAL & 57 & $100 \%$ \\
\hline
\end{tabular}

\subsection{Virtual reality}

Data collected had shown that most of the students had positive perceptions towards virtual reality (see Fig. 11). About $70 \%$ or more students agreed or strongly agreed that they could travel virtually, travel through time, practices safely, learn MEP features, learn construction safety features, grasp design concept, focus in learning and trigger design creativity. This approach to teaching has produced a positive impact on learning. First and foremost, students are relatively more enthusiastic to 
improve their design models after finding out their weaknesses in virtual reality, which was difficult, if not impossible, in conventional architectural drawings. Apart from that, virtual reality promotes collaborative learning as it allows lecturers/students based in different geographic locations to collaboratively design, review, test and validate projects virtually.

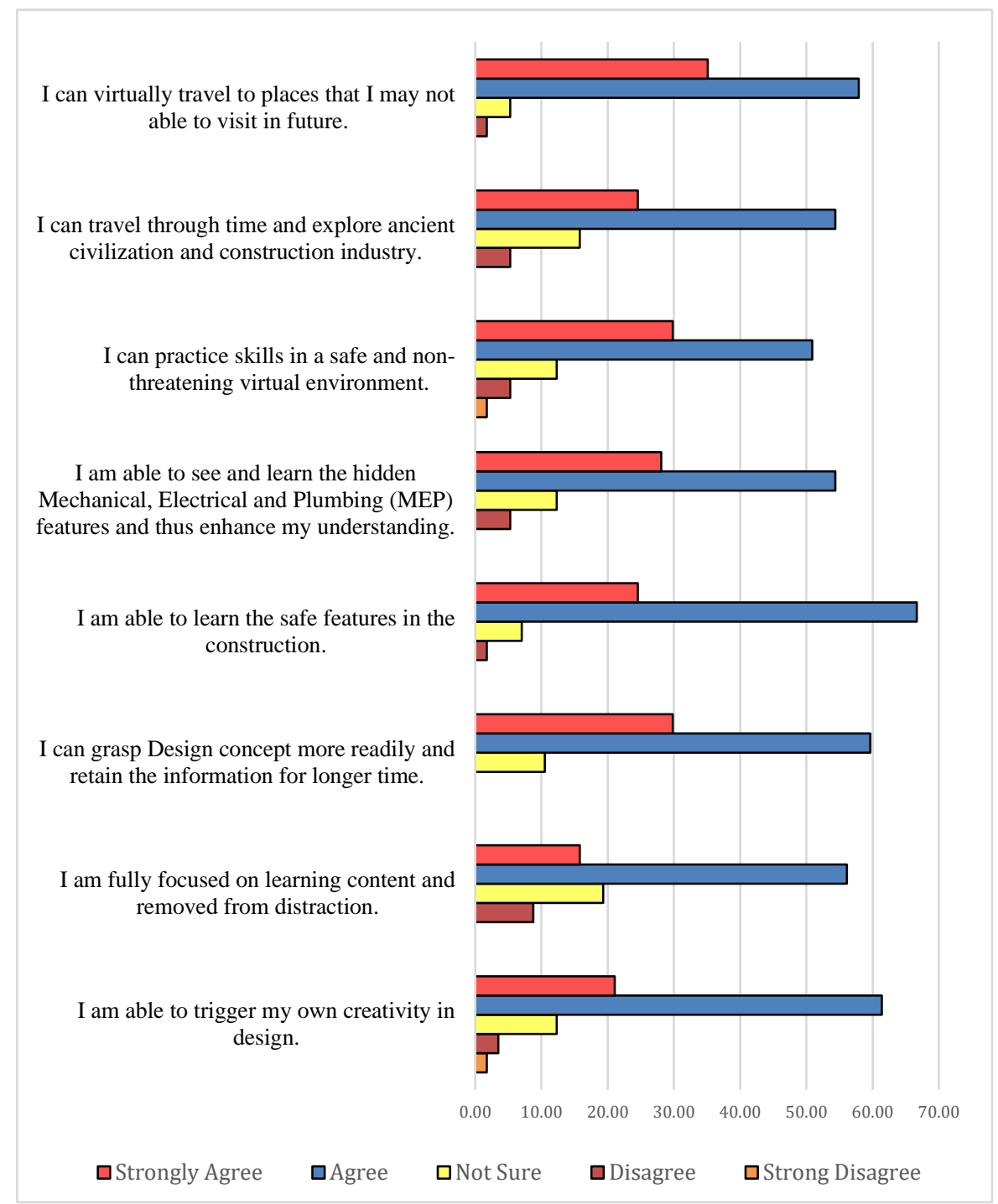

Fig. 11. Students' perceptions of augmented reality and virtual reality 


\subsection{Learning experiences}

Data collected had shown that most of the students had positive learning experiences in the BIM course (see Fig. 12). About $70 \%$ or more students agreed or strongly agreed that the BIM workshop was useful, the teacher was an effective educator and the learning environment was encouraging. Apparently, the use of augmented reality and virtual reality in the BIM course had accommodated students' diversity and motivated them to learn. Every student learned differently. They possessed different kinds of mindsets and cultural backdrop, and therefore they memorized, thought, interpreted and understood things differently. Students have a unique blend of intelligences, capabilities and skills. According Gardner's Theory of Multiple Intelligences [37], every individual differs in eight intelligences. For instance, a student may have strong spatial skills but poor in linguistic. The integration VR learning is methodologically in conformity to Theory of Multiple Intelligences and supports diverse student needs.

The objectives of the workshop were made clear/available to me.

The teaching methods used in the workshop help me to learn.

The method of assessment (coursework, practical, etc) allows me to demonstrate.

The level of the workshop is about right.

The workload on the workshop is about right.

The teacher was approachable.

The teacher was an able communicator.

The teacher was patient in explaining things which seem difficult to grasp.

The teacher retained my interest.

The teacher was helpful and supportive.

The teacher encourages me to take responsibility of my learning.

Sessions were paced appropriately.

I am satisfied with the venue and time allocation for the module.

I am satisfied with the learning support provided by the teacher.

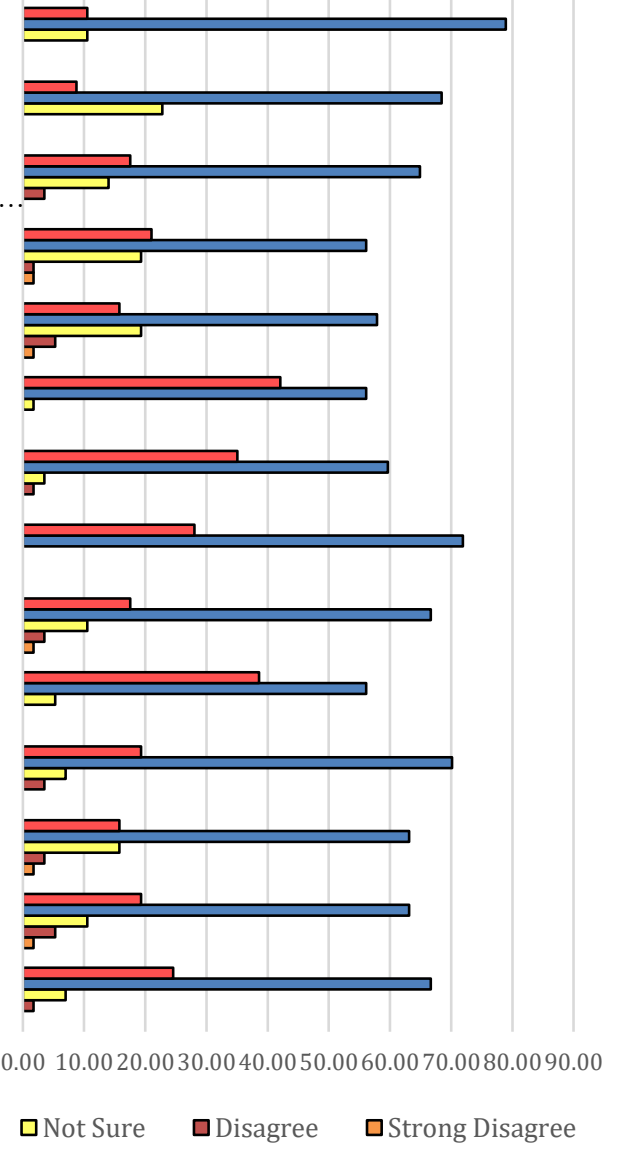

$\square$ Strongly Agree $\quad \square$ Agree $\quad \square$ Not Sure $\quad \square$ Disagree $\quad \square$ Strong Disagree

Fig. 12. Students' learning experience in BIM course 


\subsection{Gender differences}

Mann-Whitney test had shown that there were no significant differences between male and female students in 21 questions except for Q4 (see Table 2). Female students were significantly more capable in learning and understanding the hidden Mechanical, Electrical and Plumbing (MEP) feature in an augmented and virtual reality environment $(p=0.025)$. However, there were no gender differences in the other aspects of evaluations.

Table 2. Ranks of Mann-Whitney Test

\begin{tabular}{|c|c|c|c|}
\hline & \multicolumn{2}{|c|}{ Mean Rank for Gender } & \multirow[b]{2}{*}{ Asymp. Sig. (2-tailed) } \\
\hline & Male & Female & \\
\hline Q1 & 28.76 & 29.81 & 0.819 \\
\hline Q2 & 28.30 & 31.38 & 0.515 \\
\hline Q3 & 28.50 & 30.69 & 0.648 \\
\hline Q4 & 26.58 & 37.19 & $0.025^{*}$ \\
\hline Q5 & 27.38 & 34.50 & 0.101 \\
\hline Q6 & 28.18 & 31.77 & 0.432 \\
\hline Q7 & 27.73 & 33.31 & 0.237 \\
\hline Q8 & 27.69 & 33.42 & 0.209 \\
\hline Q9 & 28.42 & 30.96 & 0.495 \\
\hline Q10 & 28.50 & 30.69 & 0.609 \\
\hline Q11 & 28.44 & 30.88 & 0.583 \\
\hline Q12 & 28.34 & 31.23 & 0.539 \\
\hline Q13 & 27.66 & 33.54 & 0.208 \\
\hline Q14 & 29.85 & 26.12 & 0.410 \\
\hline Q15 & 29.67 & 26.73 & 0.516 \\
\hline Q16 & 30.07 & 25.38 & 0.251 \\
\hline Q17 & 29.10 & 28.65 & 0.918 \\
\hline Q18 & 30.98 & 22.31 & 0.059 \\
\hline Q19 & 30.16 & 25.08 & 0.228 \\
\hline Q20 & 27.53 & 33.96 & 0.154 \\
\hline Q21 & 27.49 & 34.12 & 0.141 \\
\hline Q22 & 28.56 & 30.50 & 0.655 \\
\hline
\end{tabular}

\subsection{Year of study differences}

Kruskal-Wallis test had shown that there were no significant differences among Year 1 to Year 3 students in the 22 questions (see Table 3). This could imply that students regardless of year of study were positive towards the use augmented and virtual reality in the BIM course. 
Table 3. Ranks of Kruskal-Wallis Test

\begin{tabular}{|l|l|l|l|l|}
\hline & \multicolumn{3}{|c|}{ Mean Rank for year of study } & Year 3 \\
\hline & Year 1 & Year 2 & 29.51 & Asymp. Sig. \\
\hline Q1 & 34.25 & 27.36 & 29.27 & 0.764 \\
\hline Q3 & 39.25 & 27.31 & 31.81 & 0.557 \\
\hline Q4 & 37.50 & 22.28 & 30.65 & 0.265 \\
\hline Q5 & 37.75 & 24.64 & 29.19 & 0.626 \\
\hline Q6 & 37.50 & 27.67 & 28.92 & 0.764 \\
\hline Q7 & 36.25 & 28.36 & 29.12 & 0.378 \\
\hline Q8 & 39.75 & 27.22 & 29.39 & 0.477 \\
\hline Q9 & 29.00 & 27.00 & 29.00 & 1.000 \\
\hline Q10 & 20.00 & 29.00 & 29.65 & 0.614 \\
\hline Q11 & 17.75 & 28.56 & 29.82 & 0.491 \\
\hline Q12 & 18.75 & 30.42 & 28.86 & 0.574 \\
\hline Q13 & 21.00 & 30.56 & 28.68 & 0.670 \\
\hline Q14 & 17.50 & 27.47 & 30.36 & 0.402 \\
\hline Q15 & 20.50 & 29.92 & 29.01 & 0.678 \\
\hline Q16 & 21.00 & 25.75 & 31.01 & 0.246 \\
\hline Q17 & 28.50 & 31.08 & 28.01 & 0.742 \\
\hline Q18 & 19.50 & 29.03 & 29.50 & 0.638 \\
\hline Q19 & 26.50 & 26.92 & 30.15 & 0.676 \\
\hline Q20 & 30.50 & 26.36 & 30.20 & 0.638 \\
\hline Q21 & 28.50 & 24.53 & 31.20 & 0.266 \\
\hline Q22 & 24.50 & 28.97 & 29.26 & 0.893 \\
\hline & & & & \\
\hline
\end{tabular}

\subsection{The impact of virtual reality on civil engineering learning}

With virtual reality, engineering education has a major breakthrough. Immersive interactions, stereoscopic 3D, real time multisensory simulations, virtual explorations, synchronous communications, data analytics and visual analysis - all these are hardly possible without virtual reality. Virtual reality furnishes a student-centred learning environment that promotes active and collaborative learning, situated within simulated real-world contexts. Students could explore their intellectual curiosity in ways that are seemingly impossible in traditional classroom settings. The unique blend of virtual reality and live virtual interaction creates powerful and immersive learning experiences that engage students in deeper learning.

In this VR project, an effective student-centred learning approach is being fully utilized. Learning of knowledge and skills is more meaningful when students are "learning by doing", situated within the learning context. Unfortunately, the conventional classroom lectures are usually out of context; it is analogues to someone who learns to swim by reading a book, but never got in the water. In VR however, ones could 'place themselves' in the virtual world that simulates real-world experiences. VR promotes learning through a "situated learning" approach. In a situated learning context, students develop knowledge and understanding by having concrete and hands-on experiences built on realistic problems. 
In VR, knowledge of skills, attitudes and culture in the Architecture, Engineering and Construction (AEC) industries can be constructed through problem-solving within the virtual environments and communities. VR takes the BIM model to the construction site, allowing students to learn from the first-person experience. This gives students a strong illusion of exploring and testing the viability of an architectural design, and working together with other construction professionals. The motivation behind situated learning is typically that students become participants in their own learning by deep interaction with other parties and vivid objects presented in the 3D landscape. The real-time feedback given by other parties, and the interactive environments leverage knowledge construction. The same level of control and immersion is impossible without VR.

VR allows students to explore different realities and alternate their learning experiences (instead of sitting in classroom). Furthermore, such approach is beneficial for students who are physically disabled, and to demonstrate unrealistic and dangerous simulations. Students are engaged in "active learning" and the immediate engagement is useful in understanding complex engineering theories or concepts. Exploration and hands on approach aids in learning and better retention of knowledge and skills learned.

This approach to teaching has produced a positive impact on learning. Firstly, students are more excited and enthusiastic to improve their design models after "seeing" their weaknesses in VR, which was difficult, if not impossible, in conventional architectural drawings. Secondly, VR promotes collaborative learning. VR allows lecturers/students based in different geographic locations to collaboratively design, review, test and validate projects virtually.

\section{Conclusion}

In conclusion, the BIM-VR framework provides an extensive and generic platform that promotes its use for any existing building. The application on the Trent Building in the University of Nottingham Malaysia is proof that the framework can be used generally for any existing building without the complications induced by modelling interior design piece by piece or any other time-consuming and ineffective methods; therefore, the 360-degrees inverted sphere can be an efficient substitute for these conventional interior design modelling methods. Moreover, the integrated toolkit is an important tool for data extraction from the model through the HMD and the touch controllers. So, for future work this toolkit can be extended to perform other several tasks that assist the user in the virtual environment and eliminates the need for many site visits that can be either time-consuming or inefficient in terms of cost. The platform can be improved in future research to introduce the ability to edit the BIM model in the virtual environment where this data is eventually communicated in real time to apply these changes in reality and on the actual model. The integration of the MEP systems in the model provides the opportunity for continuous monitoring of the various systems which are embedded in the walls and are extremely difficult to monitor through other methods. In this area, a continuous monitoring mechanism can be im- 
plemented in the future to predict and locate any failures in the system and avoid any disasters.

\section{Acknowledgement}

This research is supported by University of Nottingham Malaysia research grant UNEV0001entitled with 'Virtual Reality for Building Information Modelling in Engineering Education'.

\section{$7 \quad$ References}

[1] F. J. Sabongi and M. Arch, "The Integration of BIM in the Undergraduate Curriculum: an analysis of undergraduate courses," in Proceedings of the 45th ASC Annual Conference, 2009, pp. 1-4.

[2] A. Z. Sampaio, "Teaching Building Information Modelling in an Architectural School.," pp. 421-432, 2014.

[3] J. McKimm, C. Jollie, and P. Cantillon, "Web based learning," Bmj, vol. 326, no. 7394, pp. 870-873, 2003. https://doi.org/10.1136/bmj.326.7394.870

[4] M. Groves and J. O'Donoghue, "Reflections of students in their use of asynchronous online seminars,” J. Educ. Technol. Soc., vol. 12, no. 3, pp. 143-149, 2009.

[5] F. Khosrowshahi and Y. Arayici, "Roadmap for implementation of BIM in the UK construction industry," Eng. Constr. Archit. Manag., vol. 19, no. 6, pp. 610-635, 2012. https:// doi.org/10.1108/09699981211277531

[6] C. M. Eastman, C. Eastman, P. Teicholz, R. Sacks, and K. Liston, BIM handbook: A guide to building information modeling for owners, managers, designers, engineers and contractors. John Wiley \& Sons, 2011. https://doi.org/10.1002/9781119287568

[7] A. Watson, "Digital buildings-Challenges and opportunities," Adv. Eng. informatics, vol. 25, no. 4, pp. 573-581, 2011.

[8] I. Panushev, "Building information management system." Google Patents, 09-Aug-2012.

[9] J. Huval, "Evolution of Technology: Innovations in Building Information Marketing. In. SMPS Webinars: Society for Marketing Professional Services.," 2019.

[10] R. McPartland, "BIM Levels explained. In Definitions for levels of BIM maturity from Level 0, through Level 1, Level 2 and Level 3 and beyond.," Natl. Build. Specif. RIBA Enterp. Ltd., 2014.

[11] NBIMS, "National Institute of Building Sciences: National Building Information Modeling StandardTM.," Princ. Methodol., 2007.

[12] SFT, "Building Information Modelling. In Level 2 Standards. Thistle Street, Edinburgh, UK: Scottish Futures Trust.," 2019.

[13] G. Aranda-Mena and R. Wakefield, "Interoperability of building information-Myth of reality," in Proc. of the European Conference on Product and Process Modeling (ECPPM'2006), 2006, pp. 127-134.

[14] C. S. Dossick and G. Neff, "Organizational divisions in BIM-enabled commercial construction,” J. Constr. Eng. Manag., vol. 136, no. 4, pp. 459-467, 2009. https://doi.org/10. $\underline{1061 /(\text { asce }) c 0.1943-7862.0000109}$

[15] S. Azhar and S. Richter, "Building information modeling (BIM): Case studies and returnon-investment analysis," in Proceedings of the Fifth International Conference on Construction in the 21st Century (CITC-V), Istanbul, Turkey, 2009, vol. 1378, p. 1386. 
[16] J. Mitchell et al., "Adopting BIM for facilities management: Solutions for managing the Sydney Opera." Cooperative Research Centre (CRC) for Construction Innovation and the, 2007.

[17] Y. Arayici, C. O. Egbu, and S. P. Coates, "Building information modelling (BIM) implementation and remote construction projects: issues, challenges, and critiques., J. Inf. Technol. Constr., vol. 17, pp. 75-92, 2012.

[18] R. Volk, J. Stengel, and F. Schultmann, "Building Information Modeling (BIM) for existing buildings-Literature review and future needs," Autom. Constr., vol. 38, pp. 109-127, 2014. https://doi.org/10.1016/j.autcon.2014.02.010

[19] J. Steuer, "Defining virtual reality: dimensions determining telepresence.," J. Commun. Soc. Responses to Commun. Technol., vol. 42, pp. 33-56, 2000.

[20] M. Alshawi and C. W. F. C. W. Putra, "A Framework for an integrated CAD interpreter for architectural drawings," CIB W-65, Trinidad, WI, 1993.

[21] M. Alshawi and I. Faraj, "Integrating CAD and Virtual Reality in construction," in Proceedings of the Virtual Reality and Rapid Prototyping for Engineering Conference, Salford University, 1995.

[22] J. Whyte, N. Bouchlaghem, A. Thorpe, and R. McCaffer, "From CAD to virtual reality: modelling approaches, data exchange and interactive 3D building design tools," Autom. Constr., vol. 10, no. 1, pp. 43-55, 2000. https://doi.org/10.1016/s0926-5805(99)00012-6

[23] S. Wang, Z. Mao, C. Zeng, H. Gong, S. Li, and B. Chen, "A new method of virtual reality based on Unity3D," in 2010 18th international conference on Geoinformatics, 2010, pp. 15. https://doi.org/10.1109/geoinformatics.2010.5567608

[24] P. G. Schrader, "Learning in technology: Reconceptualizing immersive environments," AACE J., vol. 16, no. 4, pp. 457-475, 2008.

[25] A. Christopoulos, M. Conrad, and M. Shukla, "Increasing student engagement through virtual interactions: How?," Virtual Real., vol. 22, no. 4, pp. 353-369, 2018. https://doi.org/ $10.1007 / \mathrm{s} 10055-017-0330-3$

[26] V. S. Pantelidis, "Virtual reality and engineering education," Comput. Appl. Eng. Educ., vol. 5, no. 1, pp. 3-12, 1997.

[27] J. Abdullah, W. N. Mohd-Isa, and M. A. Samsudin, "Virtual reality to improve group work skill and self-directed learning in problem-based learning narratives," Virtual Real., pp. 111, 2019. https://doi.org/10.1007/s10055-019-00381-1

[28] W. Yan, C. Culp, and R. Graf, "Integrating BIM and gaming for real-time interactive architectural visualization,” Autom. Constr., vol. 20, no. 4, pp. 446-458, 2011. https://doi. org/10.1016/j.autcon.2010.11.013

[29] J. P. Gee, "What video games have to teach us about learning and literacy," Comput. Entertain., vol. 1, no. 1, p. 20, 2003. https://doi.org/10.1145/950566.950595

[30] D. R. Michael and S. L. Chen, Serious games: Games that educate, train, and inform. Muska \& Lipman/Premier-Trade, 2005.

[31] S. Kumar, M. Hedrick, C. Wiacek, and J. I. Messner, "Developing an experienced-based design review application for healthcare facilities using a 3D game engine," J. Inf. Technol. Constr., vol. 16, no. 6, pp. 85-104, 2011.

[32] C.-T. Chiang, C.-P. Chu, and C.-C. Chou, "BIM-enabled power consumption data management platform for rendering and analysis of energy usage patterns," Procedia Eng., vol. 118, pp. 554-562, 2015. https://doi.org/10.1016/j.proeng.2015.08.480

[33] J. H. Woo, "BIM (building information modeling) and pedagogical challenges," in Proceedings of the 43rd ASC national annual conference, 2006, pp. 12-14. 
[34] M. Ibrahim and R. Krawczyk, "The level of knowledge of CAD objects within the building information model," in Association for Computer-Aided Design in Architecture 2003 Conference, 2003, pp. 172-177.

[35] K. Lindquist and A. Khan, "Blended Learning at a Leading Executive Education Institute: State of the Practice," in E-Learn: World Conference on E-Learning in Corporate, Government, Healthcare, and Higher Education, 2002, pp. 1706-1709.

[36] B. Akkoyunlu and M. Y1lmaz-Soylu, "Development of a scale on learners' views on blended learning and its implementation process," Internet High. Educ., vol. 11, no. 1, pp. 26-32, 2008. https://doi.org/10.1016/j.iheduc.2007.12.006

[37] H. Gardner, Frames of mind: The theory of multiple intelligences. Hachette Uk, 2011

\section{Authors}

Jing-Ying Wong is affiliated with Department of Civil Engineering, University of Nottingham Malaysia. Author has interest in Building Information Modelling projects. For more details contact her at. JingYing.Wong@ @ottingham.edu.my

Chun-Chieh Yip is affiliated with Department of Civil Engineering, LKC.FES, Universiti Tunku Abdul Rahman, 43000, Kajang, Selangor, Malaysia. He is keen to know developments in area of civil.

Su-Ting Yong is affiliated with Foundation in Engineering, University of Nottingham Malaysia. The author is very patinated about learning and adopting the new developments in the education field.

Andy Chan is affiliated with Department of Civil Engineering, University of Nottingham Malaysia. He is interested in civil engineering field.

Sien-Ti Kok is affiliated with Department of Civil Engineering, University of Nottingham Malaysia. She is interested in the Civil Engineering field.

Teck-Leong Lau, is affiliated with Department of Civil Engineering, University of Nottingham Malaysia, 43500, Selangor, Malaysia.

Mohammed T. Ali, is affiliated with Department of Civil Engineering, University of Nottingham Malaysia, 43500, Selangor, Malaysia.

Essameldin Gouda, is affiliated with Department of Electrical and Electronic Engineering, University of Nottingham Malaysia, 43500, Selangor, Malaysia.

Article submitted 2020-01-23. Resubmitted 2020-02-21. Final acceptance 2020-02-21. Final version published as submitted by the authors. 